\title{
Cytokine gene polymorphism in multiple sclerosis in a hellenic population
}

\author{
Alexios Routsonis*1, Michael Daniilidis², Marina Paschalidou1, \\ Georgia Kokaraki ${ }^{3}$, Stamatia Magiria ${ }^{5}$, Eleftherios Stamboulis4, \\ Konstantinos Voumvourakis ${ }^{4}$ and Nikolaos Taskos ${ }^{1}$
}

\begin{abstract}
Address: ${ }^{1}$ Department of B Neurology, AHEPA University Hospital Aristotle University of Thessaloniki, Greece, ${ }^{2}$ Immunogenetics Laboratory, First Department of Internal Medicine, Faculty of Medicine, Aristotle University of Thessaloniki, Greece, ${ }^{3}$ Department of Genetics, Developmental \& Molecular Biology, Faculty of Sciences, School of Biology, Aristotle University of Thessaloniki, Greece, ${ }^{4}$ 2nd Neurology Department of Medicine, Faculty of Medicine, Athens University, Greece and 53rd Department of Psychiatry, Aristotle University of Thessaloniki, Greece

* Corresponding author
\end{abstract}

\author{
from International Society on Brain and Behaviour: 3rd International Congress on Brain and Behaviour \\ Thessaloniki, Greece. 28 November - 2 December 2007 \\ Published: 17 April 2008 \\ Annals of General Psychiatry 2008, 7(SuppI I):S2I7 doi:I0.II86/I744-859X-7-SI-S2I7
}

This abstract is available from: http://www.annals-general-psychiatry.com/content/7/SI/S2 I7

(c) 2008 Routsonis et al.; licensee BioMed Central Ltd.

\section{Background}

Multiple sclerosis (MS) is a chronic, complex, autoimmune, demyelinating disease that affects the Central Nervous System. Cytokine gene polymorhism according to the latest studies, may be considered as an important prognostic indicator in a vast number of autoimmune diseases.

\section{Materials and methods}

We investigated 13 cytokine gene polymorphisms in 40 $\mathrm{M} / \mathrm{S}$ patients and 104 healthy control group. From those 40 patients, 20 (group I) were presented with relapsingremitting type of the disease and the other 20 (group II) with secondary progressive type. Cytokine gene polymorhism was determined by using the PCR-SSP method (Invitrogen, Dynal, Wisconsin, USA).

\section{Results}

IL 1a - 889C/T genotype was more frequent in group I patients in comparison to group II $(80 \%$ vs $40 \%$, $\mathrm{p}<0,001)$. IL-2-330/+166 TG/TT and TNFa -308/-238 GG/ AG genotypes were also statistically more frequent in group I than in group II ( $40 \%$ vs $10 \%, \mathrm{p}<0,0001$ and $50 \%$ vs $20 \%, \mathrm{p}<0,001)$. IL1a $-889 \mathrm{C} / \mathrm{C}$ genotype and IL4Ra $+1902 \mathrm{~A} /$ A genotype were found more frequently in group
II than in group I patients $(60 \%$ vs $20 \%, \mathrm{p}<0,001$ and $80 \%$ vs $50 \%$, p $<0,0001)$.

\section{Conclusions}

These preliminary results of the present study suggest that gene polymorphism of the above cytokine may play a significant role in $\mathrm{M} / \mathrm{S}$ patients evaluation and prognosis. 